\title{
Gaudí el Tangerino. Un proyecto inédito: las misiones franciscanas de Marruecos
}

"A la memoria de mi padre"

\author{
Mustafa Akalay Nasser
}

Gaudí el Hombre

Repasar, aún de forma somera, la figura de Antonio Gaudf y Cornet, es tarea que sorprende grátamente, ya que pocas veces toparemos con una personalidad tan singular, innovadora y prolifica como la de este genial arquitecto catalán.

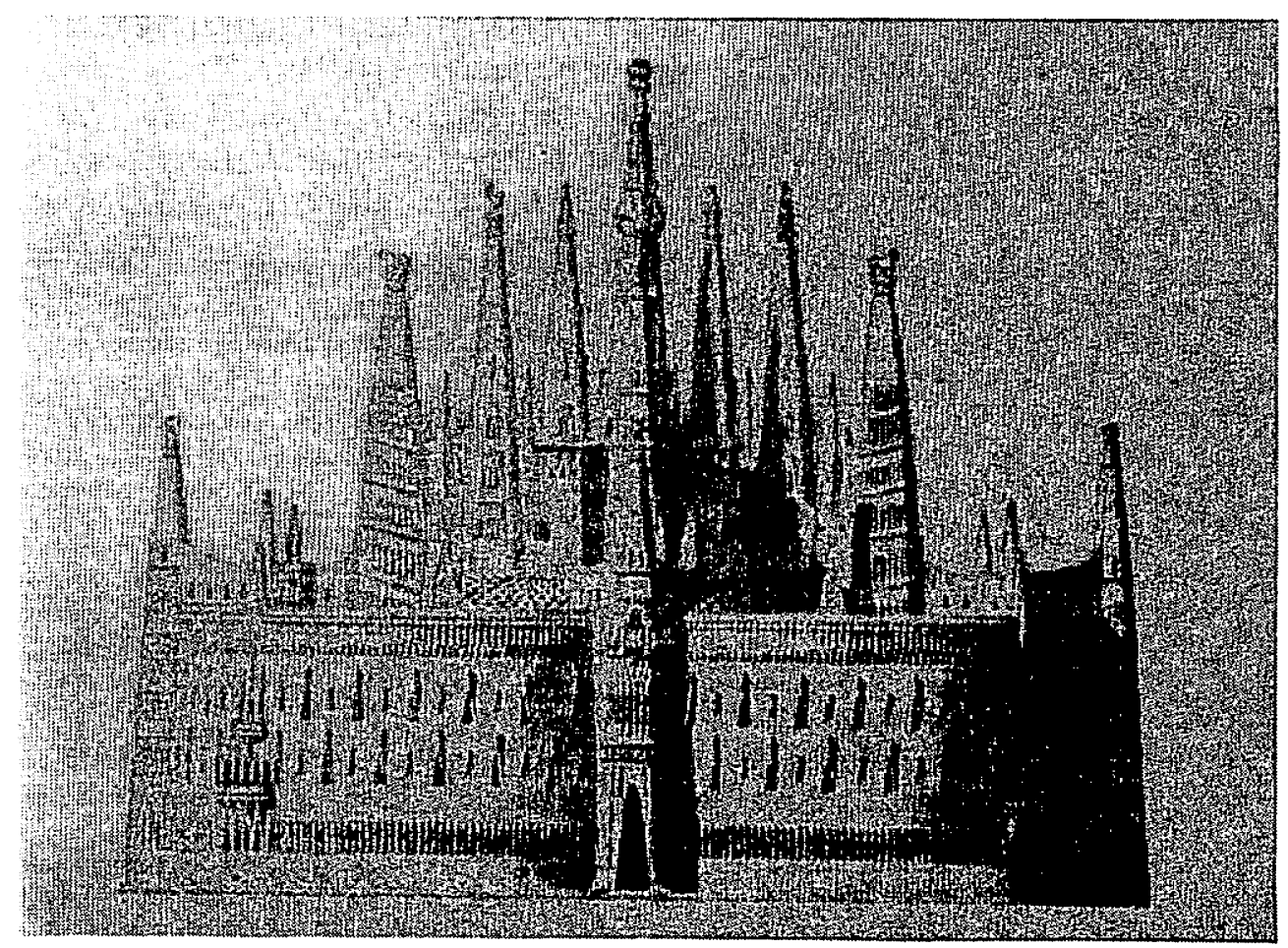

Proyecto de Gaudl para un edificio destinado a Colegio de las Misiones e Iglesia, en Tánger. 
Nace Gaudí en Reus el 25 de junio de 1852, en el seno de una familia catalana de Caldereros. ${ }^{1}$

Tras estudiar en los escolapios, viajo a Barcelona para estudiar arquitectura y obtuvo el título en 1878, no sin dificultades, ya que iba aprobando con cierta irregularidad las distintas asignaturas de la carrera

Bernardo Giner de los Ríos, autor de los cincuenta años de arquitectura española, nos retrata a un irregular, rebelde pero emprendedor estudiante Gaudf en lo que sigue: "fue lo que se llama corrientemente un mal alumno y tarda en terminar su carrera nueve años. Sus inquietudes, su afán de trabajo y observación del mundo que le rodea, hace que preste poca o ninguna atención a las clases, a cuya disciplina no se ajusta su rebeldía. Descuella en las matemáticas, pero tiene aficiones a la filosofía y a los estudios de estética. Devora libros, hace ensayos de sus ideas, todavia dentro de la escuela, con maestros de obras, especialmente con el maestro Fontseré, y son muchos los proyectos de todo tipo que realiza a su manera en su época de estudiante. ${ }^{2}$

Entre suspensos y aprobados, Antonio Gaudr termino la carrera el 14 de junio de 1877. Tras el examen final, el título de arquitecto le fue concedido el 11 de febrero de 1878. Desde esa fecha ejercio su profesion hasta tres dias antes de su muerte el 10 de junio de 1926, en el hospital de la Santa Cruz de Barcelona atropellado por un tranvia. ${ }^{3}$ En este sentido, Juan Goytisolo escribio lo siguiente: "La vilipendiada actitud de los tres choferes de taxis, que en vista de su mísero atuendo, rehusaron transportarle; la intervención del guardia civil

1. Su padre, su abuelo y su bisabuelo fueron caldereros... siempre consider fundamental su ascendencia familiar de hombres caldereros, reivindicándola a menudo como su principal fuente para ver los cuerpos directamente en el espacio y resolver en él sus problemas, sin necesitar la ayuda de la representación gráfica sobre el plano..." Salvador Tarragó, Gaudi, Barcelona, Editorial Escudo de Oro, 1983, p. 5.

2. Bernardo Giner de los Ríos, Cincuenta años de arquitectura española (II), 1900-1950, Madrid, Adir Editores, 1980, p. 31-32.

3. Gaudí tavo una triste y accidentada muerte, como lo atestigua la siguiente nota: "Gaudí, ese día lunes 7 de junio de 1926, se dispuso a cruzar la calle Cortes por el lugar que tenía costumbre. Cruzó la calzada lateral, la acera del Bulevar y la vía que correspondía al tranvía descendente. |Cuidadol - parece que le grito alguien.

Gaudr vio entonces un tranvía que se acercaba y se echó hacia atrás de forma instintiva, sin advertir que venía otro vehículo de la misma línea que circulaba en sentido de plaza Tetúan a plaza de Cataluña.

El arquitecto fue golpeado por ese segundo tranvia, dejándole malherido y tendido en el suelo.

Según el parte de la guardia urbana, Gaudí fue conducido a la Casa Socorro de la Ronda de San Pedro, donde se le practicaron las primeras curas.

En el parte se dice que los conductores de dos taxis se negaron a conducir al herido.

Gaudr, visto su estado de gravedad, fue llevado al hospital Santa Cruz...

Gaudí se fue apagando lentamente, como un cirio que quema sus últimos residuos de cera, y expiro a las cinco y ocho minutos de la tarde del día 10 de junio de 1926.":

Antonio Bueno Tello, Antonio Gaudl, Barcelona, Vilmar Ediciones, 1990, p. 139-144. 
Ramón Pérez para conducirle al puesto de socorro desde el que fue trasladado al hospital de la Santa Cruz; su célebre y simbólica agonía entre los pobres conforme a sus pros deseos". ${ }^{4}$

Su vida estuvo unida a la arquitectura, fue creador de formas, diseñador de muebles, urbanista e inventor de espacios y volúmenes.

El alarife Gaudi, fue un hombre de mediana estatura, pelo rubio y ojos azules $^{5}$ que supo ver en la naturaleza catalana un elemento de inspiracion: "a medida que fué pasando el tiempo se acercó cada vez más a lo que hoy podemos comprender que era su destino inevitable: unir, como nunca antes en la historia de la arquitectura, la forma y la estructura de los espacios, para que éstos a su vez -en forma, color y textura - se aproximaran a la misma naturaleza. $Y$ especialmente a la naturaleza que configura a Cataluna: altas cimas, corpulentos árboles, agrestes playas, soleados paseos y onduladas olas de agua cristalina". 6

La naturaleza y su desbordante imaginación dieron origen a realizaciones como la Casa Vicens (1878-1885), el Parque Güell (1900-1914), La Pedrera o Casa Milá (1906-1910), la Casa Batlló (1994-1906), todas ellas en la ciudad condal, aunque hay otras realizaciones gaudianas diseminadas por el resto de la península ibérica como el Capricho de Comillas (1883-1885), el Palacio Episcopal de Astorga (1887-1894) y por último la Casa de los Fernández-Arbós en León (1891-1894).

Esta última obra, llamada también la Casa de los Botines, es coetánea de un proyecto excepcional: las misiones franciscanas de Marruecos en Tánger.

Es precisamente en esta época cuando Antonio Gaudf comienza a desarrollar sus teorias sobre la arquitectura de adobe 0 de barro de las ciudades de las caravanas, que desembocará, meses más tarde, en la proyección del monumental edificio destinado a colegio de las misiones e iglesia de Tánger.

Imbuido de una profunda religiosidad, Gaudf quiso levantar una catedral comparable a las kasbahs o mezquitas del Africa mauritana.

\section{Marruecos: un viaje iniciático de Gaudí}

1892 será un año clave en la historia de Antonio Gaudr. Después de un viaje por Marruecos con el Marqués de Comillas, diseño un edificio destinado a

4. J. Goytisolo, Aproximaciones a Gaudt en Capadocia, Madrid, Mondadori, 1990, p. 15.

5. "Si Gaudí no hubiera tenido los ojos azules, tal vez no hubiera sido el arquitecto de la sagrada familia", A. B. Tello, op cit., p. 23.

6. Georges R. Collins, "Prólogo sobre Gaudê", in: Salvador Tarragó, op. cit. p. 3.

7. "A pesar de todo, hay una obra clarísimamente excepcional dentro de esta primera etapa, y es el proyecto para las misiones franciscanas de Marruecos en Tánger". Tokutoshi Torii, El enigmático mundo de Gaudl, Madrid, Instituto de España, 1983, p. 31.

8. Tenemos en mano, un dato fehaciente sobre la presencia de Gaudr en Tánger, gracias a la obra de P. M. López (Biografia documentada sobre Lerchundi, p. 233); “en las cuentas de la asociación de señoras españolas María Inmaculada durante los años 1888 y 1895 , es decir desde su 
iglesia e instituto de enseñanza para las misiones católicas de Africa. ${ }^{9}$

El que mejor resume la fascinación de Gaudí por lo ajeno, es su compatriota y admirador, Juan Goytisolo que nos deleita con su prosa escribiendo lo que sigue: "el espacio físico y cultural del Islám le fascinaba. Su único viaje de juventud fuera de España no fue a Paris ni siquiera a Italia sino a Marruecos. En los archivos de la escuela de la arquitectura de Barcelona en la que estudio habla fotografias de templos hindues y alminares cairotas. También le atraian las formas esbeltas de las mezquitas del Sáhara y el Sudán.

Su inspiración no fue nunca renacentista ni neoclásica: él buscaba, como Cervantes y Goya, la Espana profunda y la halló en los estratos ocultos del enjundioso mestizaje mudéjar.

El rechazo del sistema y criterios de la época le condujo a la afirmación de los valores propios frente a los universalmente acatados. Su aprendizaje de la soledad fue duro pero fecundo.

Conforme entraba en posesión de su verdad, rechazó y se alejó de la de sus paisanos.

El bon seny y avará provertá de los burgueses chocaban con la incandescencia de su fulgor místico. Paso a paso, el mudejarismo juvenil asimiló el gótico y el barroco, se explayó en una visión desconocida de la proliferante geometria de la naturaleza.

El hombre ha de sumarse constantemente, día a día, explicaba, porque la inspiración no basta, Europa no podfa aportarle ya nada; por eso se vino aqur". ${ }^{10}$

El viaje de Gaudf por Marruecos, se enmarca o mejor dicho se inscribe en esa fascinación que ejercía el mundo arábigo-musulmán, sobre escritores, poetas y artistas de la época: "con toda convicción (Gaudn) dice que no se vaya al norte a buscar el arte y la belleza; que éstas se encuentran en el Mediterráneo, de cuyas riberas - Egipto, Asiria, Grecia, Roma, España, Norte de Africa- han salido todas las obras de arte"."1

fundación hasta la muerte del padre Lerchundi, aparecen los siguientes gastos:

[...] Al Sr. Gaudí, entregado en Tánger 1.280 Pta.

Al mismo Sr. Gaudí; por su proyectos y planos

de escuelas, abonados por la Tesorería de Barcelona 10.000 Pta."

9. "Pero ¿por qué Gaudí usó Africa en vez de Marruecos? Hay dos respuestas posibles:

I. Para Gaudí y sus contemporáneos, Marruecos era sinónimo de Africa, pues la guerra acaecida en los años 1859 y 1860 entre Marruecos y España se denomina generalmente como "la guerra de Africa", y por otra parte, en una ocasión apareció la denominación "Escuelas católicas africanas" en vez de marroquíes en un acta de 1889 de la Asociación de señoras de María Inmaculada.

2ะ. Según nuestra hipótesis, Gaudí adaptó a este proyecto la tipología arquitectónica, derivada de una "aldea con muchos palomares" del Nilo, y por tanto, el honesto Gaudí aplicó Africa en lugar de Marruecos".

10. J. Goytisolo, Aproximaciones..., op cit., p. 19-20.

11. Cesar Martinell, Gaudl i la Sagrada Familia comentada por el mateix, Barcelona, 1951, p. 71. 
La peregrinación a Oriente, fue la asignatura pendiente de todo creador de finales del siglo XIX, ${ }^{12}$ que "en mal d'exotisme" y en la búsqueda de nuevos horizontes, de nuevas sensaciones o de una nueva inspiración se desplazaba a este entorno geográfico llamado Oriente, y que según el profesor palestino Edward Said está comprendido entre el Maghreb y la India, es decir el mundo islámico. ${ }^{13}$

Este es el caso también de Gaudí que en su viaje por Marruecos, descubre un mundo mágico, mitológico y simbolico, es impactado por algunos elementos caracteristicos de la estética marroqur. Tales como la fuerza de lo blanco, la estructura cúbica de las casas tetuaníes y tangerinas, la luz azulada ${ }^{14}$ y ocre, la vegetación salvaje y domesticada, las inmensidades desérticas, las soberbias y suntuosas torres de las mezquitas que abundan en el espacio urbano de Tetuán y Tánger.

En este sentido, Javier Ruiz López Puertas es más claro todavía: "Durante los últimos estertores de muerte del romanticismo y las primeras décadas del $\mathrm{XX}$, con las artes nuevas, nace un gusto por lo exótico, por el Oriente, Matisse, Delacroix, Gaudi y Picasso se inspiran en estéticas del tercer mundo aunque no siempre con fortuna, Salones de cafe turco, chales, pipas de opio y hashish, biombos y más tarde, películas como Casablanca, dan al mundo árabe una muy colorida estampa llena de señores con yil-laba y un pollo en la mano izquierda, muy folklorico y muy bonito". 15

\section{El Marqués de Comillas mecenas de un Gaudí inédito}

La gente en general, excepción hecha de un grupo cerrado de estudiosos y

12. "Desde fines del XVII, el escenario morisco, divulgado por las traducciones del Abencetraje y Pérez de Hita, seduce e inspira a los poetas, narradores y dramaturgos europeos. El exotismo ornamental de los árabes, la gallardía y pundonor de sus caudillos, la exaltación amorosa de sus amantes ponen de moda fantasías históricas y cuadros orientales protagonizados por Abencerrajes y Zegrís.

A partir de entonces, cuando el tema oriental y morisco aflore en nuestra literatura lo hará no ya en virtud de nuestra profunda intimidad con el mismo sino de forma importada y mimética, en zaga y por efecto de algún modelo anglofrancés...

Idéntico fenómeno de importación del tema árabe a través de Francia se reproducirá aún con nuestros modernistas; el decorado oriental, puro art nouveau, y su panoplia de accesorios, referencias, imágenes, objetos presuntamente poéticos, será un eco desvaído de Victor Hugo o Verlaine y no un retomo saludable a los orígenes de nuestro romancero", J. Goytisolo, Crónicas sarracinas, Paris, Ruedo Ibérico, 1982, p. 15-16.

13. E. Said, L'Orientalisme, l'Orient cré par l'Occident, Paris, Ed. du Seuil, 1980.

14. Gaudl es impresionado, como lo fue en su tiempo otro gran transeunte ilustre Mariano Fortuny (1828-1874) por esta riqueza lumínics del cielo marroqú, ver Tokutoshi Torii, El enigmático mundo, op cit. p. 59.

15. J. R. Lopez Puertas, "Aborfgene, Marnecos de la artesanfa al arte", Revista Puerta oscura (3-4), 1986, p. 17. 
tratadistas gaudinianos, ${ }^{16}$ ignoran que el ilustre y genial arquitecto Gaudf, proyectó hacia 1892 y bajo patrocinio de los marqueses de Comillas un original y formidable proyecto arquitectónico: las misiones franciscanas de Tánger.

Al segundo marqués de Comillas, ${ }^{17}$ Claudio López y Brú (1853-1925) cántabro por su padre Antonio López y López (primer marqués de Comillas y grande de España en su villa natal) y catalán por su madre, le unía una gran amistad con el santo padre Lerchundi, pro-prefecto de la santa sede en 1877.

Este último, hombre fecundo en ideas, desplegó su actividad en numerosos campos; fue arabista, ${ }^{18}$ investigador, intérprete, consejero y constructor como lo prueban sus múltiples obras, ${ }^{19}$ y preocupado por la educación de las futuras generaciones, hizo saber en una relajada y amena conversación con el marqués, ya por el año 1890 , su deseo de levantar un edificio destinado a iglesia e instituto de enseñanza en Tánger. ${ }^{20}$

16. Rafols y Folguera, Rusell Hitchcock, J. J. Seeney, J. Ll, Sert, G. R. Collins, R. Pane, Tokutoshi Torii, J. M. Dalmases, J. Matamala Flotats, C. Martinell, J. E. Cirlot, J. Bergós, J. Bassegoda, F. Chueca-Goitia.

17. "El marqués de Comillas, sin tener ninguna esperanza de éxito económico, estableció una factoría comercial en Fernando Póo (1888) y otra en Río Benito, creando otra similar en Río de Oro, origen de Villa Cisneros. También estableció una planta de producción de electricidad y otra factoría comercial en Tánger. Al visitar allı en el verano del 1891, dándose cuenta de que no había ningún farol ni la menor señal de alumbrado público en la capital diplomática del imperio marroquí, D. Claudio dió orden a su representante en Tánger. Vidal y compañía, para que comenzase los trabajos de instalación de luz eléctrica. En sólo cuatro meses, quedó terminado el espacioso edificio destinado a central y montada toda la maquinaria productora de la electricidad, los cuales bendijo el $P$. Lerchundi el día de la purísima concepción de María patrona de España y de la misión católica, pero no estaba allí el marqués mismo, sino que un retrato suyo se destacaba sobre el fondo de una hermosa corona de siemprevivas.

Pero hay una calle, que lleva el nombre de Comillas, al lado de la grandiosa mezquita mayor de Tánger que está construyéndose actualmente. Esta sería una prueba más de su personalidad, que serviría para afirmar su modo de elevar el nombre y prestigio de España en Marruecos...". Tokutoshi Torii, El enigmático mundo. op. cit., p. 65-66.

18. Una de las facetas más destacadas del padre Lerchundi (1836-1896) es la de arabista. Publico Rudimentos del árabe vulgar, que se habla en el imperio de Marruecos, Madrid, 1872; Crestomatía arábigo-española Granada, 1881; y Vocabulario español-arábigo del dialecto de Marruecos, Tánger, 1892, in: P. José María López, el padre Lerchundi, Biografía documentada, Madrid, Clásica española, 1927, pp. 3-8.

19. Obras del padre Lerchundi en Tánger: fundación de una biblioteca arábiga (1880), nueva iglesia de la purísima concepción (1880-81), hospital español provisional (1881), capilla de San Juan Bautista (1883), reforma de la escuela de niñas (1883), nuevo colegio de niños (1886), fundación de la imprenta hispano-arábiga (1886), escuela de medicina (1887), una barriada de 35 casitas baratas (1887-88), taller de carpinterfa (1887), nuevo hospital español (1887-88), nuevo edificio para la tipografía hispano-arábiga, un taller de encuademación (1888), colegio de segunda enserianza de San Buenaventura (1892), reloj público (1894), fundación de la "asociación de damas de caridad" (1895), cocina económica y comedor de caridad (1895).

20. Carta del marqués de Comillas al padre Lerchundi, con fecha 31 de julio de 1890 (archivo de Tánger, legajo Compañía Transatlántica XVII. 
Para hacer realidad dicho deseo, el marqués de Comillas, hizo venir a Marruecos, al arquitecto Gaudí, que después de pasar un tiempo inspeccionando el terreno y recorriendo las ciudades de Tánger y Tetuán diseñó el siguiente proyecto:

"Gaudr planeó para Tánger una iglesia o capilla en el centro, atendiendo a la necesidad de uno de los futuros destinos de este edificio, convento; a su alrededor dispuso cuatro espacios libres separados e independientes, uno de los cuales se destinaría a claustro para misioneros, y otro, a jardín o patio para esparcimiento y solaz de los alumnos de las escuelas, otro de los destinos del mismo; y cerrando todo, proyectó cuatro crujías en planta de medio círculo para el convento, colegio y escuelas propiamente dichos, y en su totalidad, formo una planta cuadriculada, separada en cuatro partes iguales por una gran cruz. Esta disposición de Gaudi derivaria, seguramente del emblema compuesto por las cinco cruces potenzadas: una grande en el medio y cuatro restantes, más pequenas situadas en los ángulos que forma la primera...

[...] Gaudr dispuso la puerta de entrada en cada uno de los cuatro extremos de la cruz potenzada, porque esta cruz consta de cuatro cruces de potenza o de "Tau" y en una de las visiones del apocalipsis, según San Juan, entra en la ciudad un notario y de orden del sefior va señalando con una tau a los justos, para poder en la destrucción distinguirlos de los culpables.

En el centro de los cuatro patios plante6 un círculo que posiblemente estaría destinado a una fuente como en el claustro de cualquier monasterio cristiano o en los patios de la arquitectura musulmana como si simbolizase el oasis en el desierto.

En el centro de las cuatro crujías de medio ćrculo proyectó una serie de tribunas y una aguja. Esta parte del conjunto compuesto por una crujía, una fuente y una serie de tribunas se correspondería cada una de las cuatro pequeñas cruces potenzadas. Por lo que ataffe al alzado, la necesidad de realizar el convento, el colegio y la escuela conduciría a Gaudi a proyectar el vasto edificio circundante, que consiste en las cuatro crujías en planta de medio círculo, adaptándolo a la base de una tipología arquitectónica que deriva de una "aldea con muchos palomares" en la cual los indígenas, a su vez, construyeron la base para sus habitaciones. ${ }^{21}$ En cambio, la parte de las torres en esta tipología arqui-

21. "Este proyecto para las "Misiones Católicas de Africa" es una clave trascendental en la creación y en el progresivo desarrollo arquitectónico de Gaudí, porque de él nacieron directamente la iglesia de la colonia Guell y el Templo Expiatorio de la Sagrada Familia. Si Gaudí no se hubiese encargado de realizar este proyecto, las dos obras mencionadas tendrian unas fisonomías totalmente diferentes a las proyectadas y realizadas. Gaudí buscaba intensa y conscientemente una tipología arquitectónica caracteristica y adecuada a la tierra de Africa, exclusiva para este proyecto tangerino; por eso, y gracias a un accidente histórico, pudo encontrar "una aldea con muchos palomares" dibujada por Ali Bey, y, sin este proyecto, no se le hubiera ocurrido buscar aquella tipología a lo largo do todo el continente africano, y ni siquiera hubiera hecho caso del dibujo de Domingo 
tectónica debe estar en perfecta consonancia con su concepto formativo del templo cristiano". 22

Para realizar este proyecto se creó una "asociación de sefioras españolas de María Inmaculada", presidida por la Marquesa de Comillas, María Andrés Gayón y Berner, y cuyo objetivo principal era recoger los fondos indispensables para atender a las más apremiantes necesidades ${ }^{23}$ de la misión de Marruecos como lo prucba la siguiente nota;

"Varios son los proyectos que, prosiguiendo su laudibilísima empresa, se propone realizar la asociación de señoras españolas, tales como la construcción del monumental edificio destinado a iglesia e instituto de ensefianza, y otros no menos importantes.

Las personas que quieran cooperar en esta obra nacional y benéfica de auxiliar los esfuerzos de la misión católica-española en Marruecos, pueden depositar sus limosnas en las casas del excmo. señor Marqués de Comillas, Plaza de la Independencia, $n^{2}$ 5, Madrid, y Puerta Ferisa, no 3, Barcelona...".24

Desgraciadamente por razones no obvias y todavia confusas, y a pesar del empeño constante del padre Lerchundi y los marqueses de Comillas; éste formidable proyecto quedó en agua de borrajas, y por suerte lo podemos comprobar hoy día gracias al dibujo original, descubierto recientemente (febrero 1991), por todos nosotros ${ }^{25}$ en Tánger, en un álbum de grabados sobre Marruecos, dedicado al padre Lerchundi y editado en Barcelona en 1897, cuyo diseño ha visto el lector en la página primera.

Aparte de este grabado original, hay constancia también de otros dos testimonios gráficos de este proyecto revelados por el nipón y tratadista gaudiniano Tokutoshi Torii en 1983; "hasta ahora, sólo hay dos datos concretos e irrefuta-

Badía, aunque casualmente lo tuviese a su vista, de modo que Gaudí no hubiera tenido ocasión de introducirlo en su proceso arquitectónico.. Es muy curioso, o puede ser algo muy normal del prejuicio humano con el cual generalmente se miran y juzgan las obras, que ningún tratadista gaudiniano haya podido adivinar la existencia de una fisonomía fuertemente africana en la Colonia Guell y la Sagrada Familia, mientras que todo el mundo, incluso extraños, ven e indican algo muy africano en el proyecto de Tánger siempre que hablan de él. Será porque las dos primeras obras son para Cataluña, que no tiene nada que ver con Africa, mientras que la última fue destinada a Tánger, lo que obligará a no pasar por alto dicho continente. Pero Gaudr era consciente de este punto, por eso su ferviente mediterraneísmo incluyó siempre a Egipto y de vez en cuando al Norte de Africa", in: Tokutoshi Torii, El enigmático nundo, op cit., p 173.

22. Tokutoshi Torii, ibidem, p. 126-127.

23. P. M. López: El padre Lerchundi, biografla documentada, Madrid, Imprenta clásica española, 1927, p. 216-217.

24. Juan Menéndez Pidal, Misiones católicas de Marruecos, album hispano-marroqul, Barcelona, 1897 , p. 31.

25. El padre Ramón Lourido Díaz, historiador, Jaume Bover, director de la Biblioteca española de Tánger, Mustafá Akalay Nasser, urbanista y autor del presente trabajo. 
bles sobre este proyecto; casi todos los tratadistas gaudinianos dicen que este proyecto data de los años 1892 y 1893 , porque el dibujo original en que figuraba el alzado y la planta del edificio llevaba la fecha, "Barcelona $1892=1893$ ", y, por suerte, lo podemos probar actualmente gracias a la fotografía tarjeta postal de este proyecto enviada por Gaudl de su puno y letra a Mariano Andrés (copropietario de la Casa de los Botines de León).

Esta foto, que ahora se conserva en la Cátedra Gaudí en la Escuela Técnica Superior de Arquitectura de Barcelona, y un grabado, que se publicó en el primer libro sobre Antonio Gaudf de Rafols (Barcelona, Canosa 1929, p. 87), son los únicos datos gráficos de este proyecto que conozcamos hasta ahora, pues todos los documentos y planos que se conservaban en el templo de la Sagrada Familia se quemaron en 1936 al comienzo de la guerra civil de España....".26

26. Tokutoshi Torii, El enigmático mundo, op. cit., p. 32. 